\title{
A new non-resonant laser-induced fluorescence instrument for the airborne in situ measurement of formaldehyde
}

\author{
Jason M. St. Clair ${ }^{1,2}$, Andrew K. Swanson ${ }^{1,3}$, Steven A. Bailey ${ }^{1}$, Glenn M. Wolfe ${ }^{1,2}$, Josette E. Marrero ${ }^{4}$, \\ Laura T. Iraci ${ }^{4}$, John G. Hagopian ${ }^{5,6}$, and Thomas F. Hanisco ${ }^{1}$ \\ ${ }^{1}$ Atmospheric Chemistry and Dynamics Laboratory, NASA Goddard Space Flight Center (GSFC), Greenbelt, MD 20771, \\ USA \\ ${ }^{2}$ Joint Center for Earth Systems Technology, University of Maryland Baltimore County, Baltimore, MD 21228, USA \\ ${ }^{3}$ Goddard Earth Sciences Technology and Research, Universities Space Research Association, Columbia, MD 21046, USA \\ ${ }^{4}$ Atmospheric Science Branch, NASA Ames Research Center, Moffett Field, CA 94035, USA \\ ${ }^{5}$ Lambda Consulting-Advanced Nanophotonics, Harwood, MD 20776, USA \\ ${ }^{6}$ Optics Branch, Instrument Systems and Technology Division, NASA Goddard Space Flight Center, Greenbelt, \\ MD 20771, USA
}

Correspondence: Jason M. St. Clair (jason.m.stclair@nasa.gov)

Received: 31 July 2017 - Discussion started: 4 August 2017

Revised: 2 October 2017 - Accepted: 14 October 2017 - Published: 12 December 2017

\begin{abstract}
A new in situ instrument for gas-phase formaldehyde (HCHO), COmpact Formaldehyde FluorescencE Experiment (COFFEE), is presented. COFFEE utilizes nonresonant laser-induced fluorescence (NR-LIF) to measure $\mathrm{HCHO}$, with $300 \mathrm{~mW}$ of $40 \mathrm{kHz} 355 \mathrm{~nm}$ laser output exciting multiple $\mathrm{HCHO}$ absorption features. The resulting $\mathrm{HCHO}$ fluorescence is collected at $5 \mathrm{~ns}$ resolution, and the fluorescence time profile is fit to yield the ambient $\mathrm{HCHO}$ mixing ratio. Typical $1 \sigma$ precision at $\sim 0$ pptv $\mathrm{HCHO}$ is $150 \mathrm{pptv}$ for $1 \mathrm{~s}$ data. The compact instrument was designed to operate with minimal in-flight operator interaction and infrequent maintenance (1-2 times per year). COFFEE fits in the wing pod of the Alpha Jet stationed at the NASA Ames Research Center and has successfully collected HCHO data on 27 flights through 2017 March. The frequent flights, combined with a potentially long-term data set, makes the Alpha Jet a promising platform for validation of satellite-based column HCHO.
\end{abstract}

\section{Introduction}

Formaldehyde (HCHO) is an abundant, photochemically influential trace species in the Earth's atmosphere. Primary sources of HCHO include biomass burning (Akagi et al.,
2011; Andreae and Merlet, 2001) and fossil fuel combustion (Anderson et al., 1996; Luecken et al., 2012; Olaguer et al., 2009), but these are dwarfed by secondary production from the photochemical oxidation of volatile organic compounds (VOCs). This secondary source is dominated by the locally abundant $\mathrm{VOC}(\mathrm{s}): \mathrm{CH}_{4}$ in the remote atmosphere, isoprene in biogenically active regions (Palmer et al., 2003; Shim et al., 2005), and unsaturated (Parrish et al., 2012) VOCs in regions with large anthropogenic VOC emissions. HCHO loss occurs via photolysis and reaction with $\mathrm{OH}$, resulting in a daytime atmospheric lifetime of a few hours. Mixing ratios of $\mathrm{HCHO}$ vary from tens of parts per trillion (pptv) in the remote atmosphere (Fried et al., 2003) to a few parts per million by volume (ppmv) in biomass burning plumes (Akagi et al., 2014), with typical values in the 50 pptv to 10 ppb range. Elevated $\mathrm{HCHO}$, due to its limited atmospheric lifetime, is indicative of recent VOC oxidation, and in the upper troposphere and lower stratosphere it suggests recent convective transport (Apel et al., 2012; Fried et al., 2008b, 2016). Measurements of $\mathrm{HCHO}$ are valuable both as a tracer of recent VOC oxidation and also due to its role in $\mathrm{HO}_{x} / \mathrm{O}_{3}$ chemistry (Jaeglé et al., 2001).

Atmospheric HCHO is measured using a variety of airborne instrumental methods, including mass spectrometry (Warneke et al., 2011), wet chemistry (Aiello and McLaren, 
2009; Junkermann and Burger, 2006; Lazrus et al., 1988), absorption spectroscopy (Baidar et al., 2013; Catoire et al., 2012; Richter et al., 2015; Washenfelder et al., 2016; Weibring et al., 2006; Yokelson et al., 1999), and laser-induced fluorescence (LIF) (Cazorla et al., 2015; Hottle et al., 2009; Mohlmann, 1985). In addition to airborne observations, total column HCHO is measured by satellite (Chance et al., 2000; Steck et al., 2008), making HCHO one of the few VOCs observable from space. Numerous measurement technique reviews and instrument intercomparisons are available (Fried et al., 2008a; Hak et al., 2005; Kaiser et al., 2014; Zhu et al., 2016).

Traditionally, LIF measurements of HCHO have used a wavelength-tunable excitation laser to dither on and off the $\mathrm{HCHO}$ absorption feature, using the difference in signal to calculate the $\mathrm{HCHO}$ mixing ratio. The benefit of this approach is that the differential signal excludes any broadband background fluorescence from interfering with the $\mathrm{HCHO}$ measurement. The downside is that it requires either a large laser system unsuited for compact airborne instrumentation (Mohlmann, 1985) or a custom, high-cost fiber laser (Cazorla et al., 2015; Hottle et al., 2009). We present a new approach to the measurement of HCHO by non-resonant laserinduced fluorescence (NR-LIF), using a fixed-wavelength $\mathrm{UV}$ industrial laser at $355 \mathrm{~nm}$ to excite multiple $\mathrm{HCHO}$ absorption features simultaneously. Lacking the tunability and narrow linewidth necessary to dither on and off a single absorption feature, selectivity to HCHO is instead obtained using specialized fluorescence optical filters and by employing high-temporal-resolution data acquisition to uniquely identify $\mathrm{HCHO}$ by its characteristic fluorescence lifetime.

The new NR-LIF HCHO instrument, COmpact Formaldehyde FluorescencE Experiment (COFFEE), was designed specifically to join the payload of the Alpha Jet Atmospheric eXperiment (AJAX) out of the NASA Ames Research Center in Mountain View, CA. The robust optomechanical design of the COFFEE instrument, combined with its simple and reliable operation, makes the instrument ideal for long-term deployment to the NASA Ames Research Center with minimal maintenance. The routine, long-term nature of the AJAX project, with flights approximately every 2 weeks, makes the Alpha Jet a good platform for monitoring seasonal and longterms trends, as well as for providing an extensive in situ data set for satellite validation.

\section{Measurement technique}

The COFFEE instrument uses NR-LIF for the detection of HCHO. Previous LIF-based instruments for atmospheric $\mathrm{HCHO}$, such as the NASA In Situ Airborne Formaldehyde (ISAF) instrument (Cazorla et al., 2015), have used a narrowbandwidth, state-specific tunable excitation laser to target a specific absorption feature. COFFEE, in contrast, employs a moderate-bandwidth (full width at half maximum, (a)
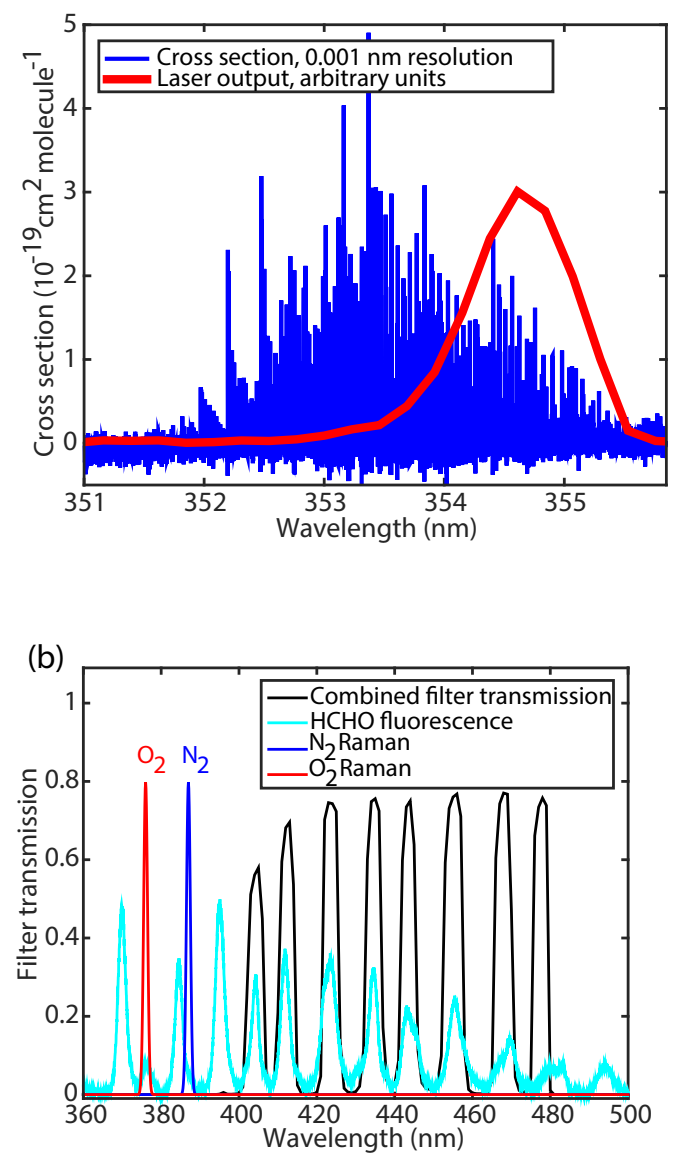

Figure 1. (a) The HCHO absorption spectrum (Co et al., 2005), averaged to $0.001 \mathrm{~nm}$ resolution, and the excitation laser spectrum are shown. (b) The optical filter transmission spectrum is shown for the detection axis 2 (multi-band-pass filter). The HCHO fluorescence and the $\mathrm{N}_{2}$ and $\mathrm{O}_{2}$ Raman spectra are included for reference, all with arbitrary units.

FWHM, $\sim 1 \mathrm{~nm}$ ) fixed-wavelength laser that excites multiple HCHO absorption features. The HCHO absorption cross section from Co et al. (2005), averaged to $0.001 \mathrm{~nm}$ resolution, is shown with the overlapping COFFEE laser output in the top panel of Fig. 1. The commercial off-the-shelf fixedwavelength laser is both less expensive and operationally more reliable than the narrow-bandwidth tunable laser. In flight operation, the laser turns on at the beginning of the flight and off at the end, with no other interaction.

HCHO fluorescence occurs over the $\sim 355-550 \mathrm{~nm}$ wavelength range, as shown in Fig. 1b. COFFEE has two detectors for collecting the banded fluorescence. Optical filter details are included in Sect. 3.2. Detection axis 1 uses a band-pass filter centered at $450 \mathrm{~nm}$ (Fig. S1 in the Supplement) to collect as much $\mathrm{HCHO}$ fluorescence as possible while excluding the primary sources of background counts (chamber, Raman, and Rayleigh scatter). Detection axis 2 (Fig. 1b) utilizes a 
multi-band-pass filter that selectively transmits at $\mathrm{HCHO}$ fluorescence wavelengths, maximizing detection selectivity at the expense of decreased sensitivity.

Other LIF-based instruments for atmospheric $\mathrm{HCHO}(\mathrm{Ca}-$ zorla et al., 2015; Hottle et al., 2009) collect fluorescence using a long-pass filter to exclude scatter and achieve measurement selectivity by alternately tuning the narrow-bandwidth laser on and off an HCHO absorption feature. The fixedwavelength laser in COFFEE cannot provide on and off line measurements. Measurement specificity to $\mathrm{HCHO}$ is instead achieved by acquiring the time-resolved fluorescence signal, $5 \mathrm{~ns}$ bins for $500 \mathrm{~ns}$, and leveraging the unique fluorescence lifetime of $\mathrm{HCHO}$ in data processing. The details of data acquisition and data processing are discussed in Sect. 3.4 and 3.5 , respectively.

\section{Instrument description}

\subsection{Laser}

A Spectra-Physics Explorer (EXPL-355-300-E, Fig. 2, item A) provides $300 \mathrm{~mW}$ of $355 \mathrm{~nm}$ of pulsed radiation at $40 \mathrm{kHz}$ (adjustable $20-60 \mathrm{kHz}$ ). The laser is actively Q switched, with a Nd: $\mathrm{YVO}_{4}$ gain medium pumped by a single $808 \mathrm{~nm}$ diode to provide the $1064 \mathrm{~nm}$ fundamental wavelength. UV output at $355 \mathrm{~nm}$ is created using two intracavity lithium triborate crystals for second and third harmonic generation. The pulse width (FWHM) is $<15 \mathrm{~ns}$, and the bandwidth is $\sim 1 \mathrm{~nm}$. The laser is compact, with head dimensions $16.5 \mathrm{~cm} \times 9.5 \mathrm{~cm} \times 5.4 \mathrm{~cm}(0.9 \mathrm{~kg})$ and power supply dimensions $16.4 \mathrm{~cm} \times 13 \mathrm{~cm} \times 6.6 \mathrm{~cm}(1.2 \mathrm{~kg})$. Computer control is via RS232.

The laser head requires proper thermal management for the laser to perform to specification. A total of $40 \mathrm{~W}$ of heat must be removed from the laser head at its maximum operating temperature of $308 \mathrm{~K}$. Two thermoelectric cooler (TEC) devices (TE Technology) provide thermal control of the laser head. The laser side of the TECs is controlled to $303 \mathrm{~K}$, and the other side of the TECs are in thermal contact with the optical plate and heat sinks mounted to the underside of the optical plate.

\subsection{Optical system}

The optical layout of the instrument (Fig. 2, item B) is shown in more detail in Fig. 3. The entire optical system is contained on the optical plate in a single plane. The plate was machined out of $13 \mathrm{~mm}$ thick 6061 aluminum and is secured to the chassis at four points utilizing Sorbothane vibration isolation bushings. The plate is heated to $303 \mathrm{~K}$.

The laser beam is directed by two antireflection (AR)coated dielectric mirrors (CVI Laser Optics) into the detection cell. A collimating lens $(\mathrm{F}=100 \mathrm{~mm}$, Thorlabs) and a $\lambda / 2$ wave plate (AR coated, OptiSource), with the latter used to minimize the Raman scattering directed at the photomul- tiplier tubes (PMTs), are positioned in between the turning mirrors. The detection cell is very similar to the cell in ISAF (Cazorla et al., 2015), with the main differences being the number and orientation of the PMTs and the optical filters used. The beam enters and exits the cell through AR-coated fused silica windows (CVI Laser Optics) that are mounted at a $3.5^{\circ}$ angle to prevent surface reflections from reaching the PMTs. Inside the cell, the beam continues through a series of circular baffles, four before the detection volume and three after, which drastically reduce stray light. The baffle apertures are progressively larger along the beam propagation path $(2.5,3.0,3.5 \mathrm{~mm})$. The baffles adjacent to the detection volume are coated with a carbon nanotube coating (Hagopian, 2011); the other baffles are laser-cut and painted black (Lenox Laser). The interior of the detection cell is coated with a molybdenum oxide treatment (InstaBlak 380; Electrochemical Products, Inc.) to further eliminate stray light.

On two sides of the detection cell, aspheric lenses (NA $=0.66$, AR coated, Edmund Optics) image the volume where the laser beam and main gas flow cross. From each lens, the image is reflected $90^{\circ}$ by a turning mirror (right angle prism dielectric, Thorlabs) and passed through a series of optical filters before being partially focused by a lens ( $\mathrm{F}=75 \mathrm{~mm}$, AR coated, Thorlabs) onto a photomultiplier tube (Hamamatsu H7360-02 MOD). The optical filters differ between the two PMTs. Arranged in order from the aspheric lens to the PMT, axis 1 contains an AR-coated $370 \mathrm{~nm}$ longpass absorption filter (Hoya Candeo Optronics); a $450 \mathrm{~nm}$, $70 \mathrm{~nm}$ wide band-pass interference filter (Semrock); and a $395 \mathrm{~nm}$ long-pass absorption filter (Edmund Optics). Axis 2 uses a $400 \mathrm{~nm}$ long-pass interference filter (Omega Optical), an AR-coated $370 \mathrm{~nm}$ long-pass absorption filter (Hoya Candeo Optronics), a custom 11-band band-pass interference filter (Semrock), and a $395 \mathrm{~nm}$ long-pass absorption filter (Edmund Optics). The 11-band filter was designed to selectively transmit formaldehyde fluorescence while reducing the background. After the detection cell, a beam sampler (Thorlabs) splits the beam, and the main beam continues to a beam dump. The beam sampler reflection is directed to a power meter consisting of a diffuser (Thorlabs DGUV10-600), an absorption filter (Thorlabs FGUV11), and an amplified photodiode (OSI 555-UV).

\subsection{Gas handling}

The fundamental design consideration for the instrument sample flow is to minimize the potential for the adsorption/release of $\mathrm{HCHO}$ to/from exposed surfaces (Cazorla et al., 2015; Wert et al., 2002). To that end, all surfaces that deliver gas to the detection cell are either fluorocarbon (FEP, THV) or fluorocarbon coated (FluoroPel, Cytonix). The current Alpha Jet inlet is a $9.5 \mathrm{~mm}$ OD (6 mm ID) rear-facing stainless steel tube that extends $17 \mathrm{~cm}$ beyond the bottom of the pod. A $9.5 \mathrm{~mm}$ OD $(6.35 \mathrm{~mm}$ ID) THV fluoropoly- 


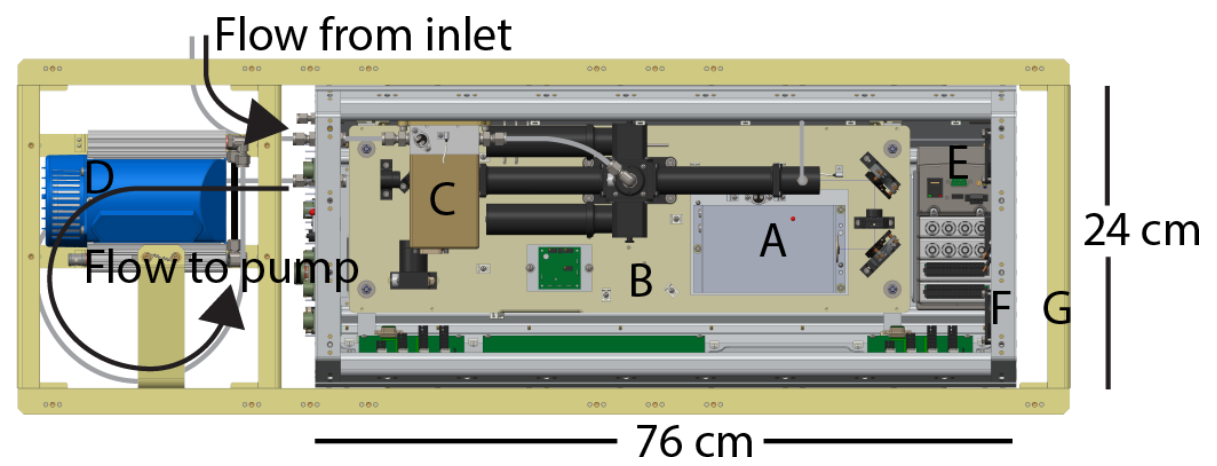

Figure 2. COFFEE instrument layout in the AJAX pod rack, including the (a) laser, (b) optical plate, (c) pressure controller, (d) vacuum pump, (e) RIO data acquisition system, (f) instrument chassis, and (g) AJAX pod rack.

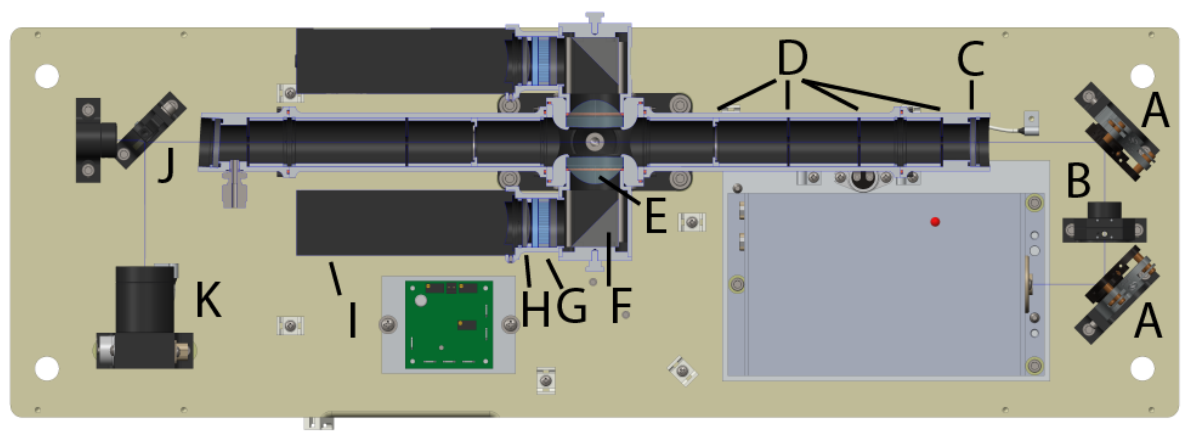

Figure 3. The optical plate layout is shown, with a cutaway of the detection cell. The components include the (a) steering mirrors, (b) half-wave plate and collimating lens, (c) cell windows, (d) laser baffles, (e) aspheric lens, (f) prism dielectric mirror, (g) optical filters, (h) lens, (i) photomultiplier tube, (j) beam splitter, and (k) laser power monitor.

mer tubing connects the inlet to the instrument chassis. The instrument is operated with an inline particle filter (Balston 9922-05-DQ) to minimize related measurement artifacts from high aerosol loading (see Sect. 4.5). The filter housing is Kynar (polyvinylidene fluoride) and the filter element is a microfiber with a fluorocarbon resin binder. The element retains $93 \%$ of the particles with a $0.01 \mu \mathrm{m}$ diameter. The transmission of $\mathrm{HCHO}$ by the particle filter was tested with the calibration system and found to be $100 \%$.

Inside the instrument, $5 \mathrm{~cm}$ of $9.5 \mathrm{~mm}$ OD PFA tubing connects from the chassis to a pressure controller, and $15 \mathrm{~cm}$ of $9.5 \mathrm{~mm}$ OD PFA tubing connects from the pressure controller to the detection cell. The pressure controller (Fig. 2, item C) is an actuator (iQ Valves) coupled with a custom valve block and is heated to $308 \mathrm{~K}$. The detection cell pressure is regulated to $10.7 \mathrm{kPa}$. The main flow passes directly down through the detection cell and out of the chassis to the vacuum pump (Vacuubrand MD-1; Fig. 2, item D). A small amount of air is pulled through the laser baffle arms to flush that volume, and the flow is combined with the main flow (after the detection cell) before exiting the chassis. In lab, the instrument sampling flow is 2.3 standard $\mathrm{L} \mathrm{min}^{-1}$.

\subsection{Data acquisition}

Data acquisition and instrument control is conducted by a National Instruments (NI) CompactRIO system, hereafter RIO (Fig. 2, item E). The RIO consists of a main processor module (running a realtime operating system) and a backplane driven by a field programmable gate array (FPGA). Additional plugin modules add I/O. NI 9205 and NI 9264 modules provide analog input and output, respectively. Two channels of an NI 9402 high-speed digital I/O module are programmed as $5 \mathrm{~ns}$ resolution counters, with each PMT having its own counter. The counters are triggered by the OptoSync from the laser (30-100 ns after the laser pulse), which provides a digital logic pulse closer in coincidence with the laser light pulse than obtained from the "trigger out" logic pulse synchronous with the laser trigger. In order for the PMT signals to arrive after the counters are triggered, they are delayed by $50 \mathrm{~ns}$ with a passive delay circuit (Data Delay Devices, 1515 series).

Data for each PMT channel are acquired in two ways: (1) integrated every $0.1 \mathrm{~s}$ with ungated (continuous) and gated data streams, which are used primarily for diagnostic purposes; and (2) integrated every $1 \mathrm{~s}$ and time resolved to 100 discrete time bins, each $5 \mathrm{~ns}$ wide, that cover the $500 \mathrm{~ns}$ 
immediately following the counter trigger. The $5 \mathrm{~ns}$ timeresolved data are the key to the data processing approach necessary to minimize measurement artifacts with the NRLIF approach, as will be discussed in Sect. 3.5, and are used to produce the HCHO mixing ratio data product. Diagnostic data (laser power, pressures, temperatures, etc.) are also recorded every $1 \mathrm{~s}$.

\subsection{Data processing}

$\mathrm{HCHO}$ mixing ratios are obtained using the $5 \mathrm{~ns}$ bin timeresolved profiles from the two detection axes. The data processing consists of three steps, each done independently for the two detection axes: (1) subtraction of the minor "longlived" component from the time profile; (2) two-parameter nonlinear least squares fit of the data using profiles (hereafter referred to as exemplars) that represent the $\mathrm{HCHO}$ and nonHCHO (chamber scatter, Raman and Rayleigh scatter, fluorescence of optics, etc.) contributions to the observed profile; (3) one-parameter nonlinear least squares fit with the non$\mathrm{HCHO}$ contribution fixed from the previous two-parameter fit and only the HCHO contribution allowed to vary. The second pass fit with only one parameter improves the precision of the measurement. In addition to the fitting-based data processing, HCHO mixing ratios can also be obtained from gated count data, as discussed in Sect. 3.5.3.

\subsubsection{Long-lived component}

The fluorescence signal at the end of the bin-resolved data ( $>400 \mathrm{~ns}$ ) is small but nonzero, and changes in this long-lived signal do not scale with changes in the non-HCHO "air exemplar", necessitating a separate treatment. The long-lived signal has a longer fluorescence lifetime than $\mathrm{HCHO}$, which permits fitting and removal of the long-lived signal without interference from ambient HCHO. For detection axis 1, an empirical profile determined from a laboratory run is scaled to fit the observed $1 \mathrm{~Hz}$ data using a single parameter least squares fit to the observed profile from bin 75 to bin 100 (370-500 ns), and the scaled profile is subtracted from the observed data before performing the exemplar fits. For detection axis 2, the long-lived signal is smaller than for axis 1 by a factor of $\sim 6$ and is stable over the last $\sim 15$ bins, and so a simpler treatment is used: the observed $1 \mathrm{~Hz}$ profile is averaged from bin 87 to bin $100(430-500 \mathrm{~ns})$ and the mean is subtracted as a constant from all bins in the observed profile before performing the exemplar fits. Examples of time profile data for both detection axes along with their respective longlived components are shown in Figs. S2 and S3. All fitting and exemplar creation is done using data with the long-lived component removed.

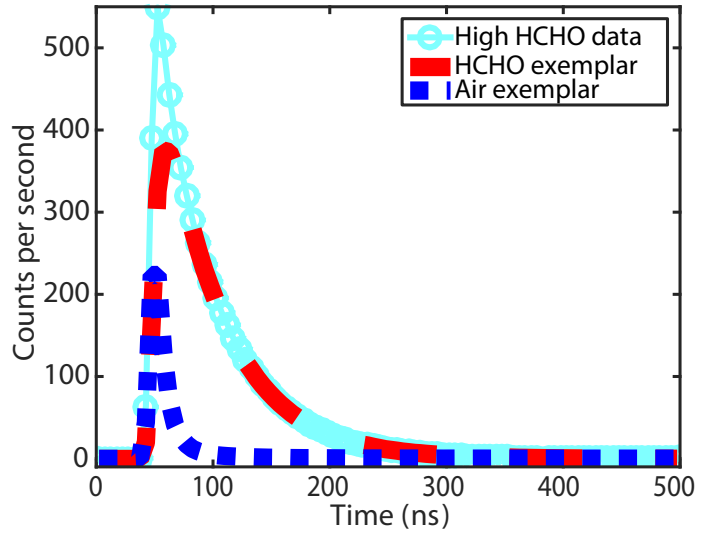

Figure 4. Exemplar time profiles are obtained in the laboratory. The air exemplar is created by averaging the profile with no added HCHO (blue dashed line), and the HCHO exemplar (red dashed line) is obtained by subtracting the air exemplar from data with high (29 ppbv) HCHO (cyan circles).

\subsubsection{Exemplar fits}

\section{Obtaining the exemplars}

The representative time profiles, or exemplars, are determined from laboratory calibration runs where the instrument samples clean, dry air (typically ultra-high purity, UHP, dry air) with varied amounts of $\mathrm{HCHO}$ added. The air exemplar, which represents all non-HCHO contributions to the observed profile, is obtained by time averaging the observed profile when no $\mathrm{HCHO}$ is added to the dry air. Figure 4 shows the profiles involved in creating the "HCHO exemplar". The HCHO exemplar (Fig. 4, red dashed) is obtained by time averaging the observed profile (Fig. 4, cyan circles) during the calibration period of maximum $\mathrm{HCHO}$ (typically 25-30 ppbv) and subtracting the air exemplar (Fig. 4, blue dashed) from the time-averaged profile. The highest $\mathrm{HCHO}$ period is used so that $\mathrm{HCHO}$ dominates the shape of the observed profile. Once the air and HCHO exemplars are obtained, they are used to fit laboratory calibration data with multiple $\mathrm{HCHO}$ concentrations using the two-step fit described below. The calibration factor unique to this $\mathrm{HCHO}$ exemplar is obtained from the linear regression of the $\mathrm{HCHO}$ added by the calibration system and the HCHO exemplar scaling factor, which is the output of the fit.

\section{Two-parameter exemplar fit}

An example two-parameter exemplar fit is shown in Fig. 5. The observed profile (Fig. 5, cyan circles), with the longlived component removed, is fit with a linear combination of the air exemplar and the HCHO exemplar. The fit parameters are the scalar multipliers applied to the exemplars: the scaled air exemplar (Fig. 5, blue dashed) and scaled HCHO exemplar (Fig. 5, red dashed). The least squares optimiza- 


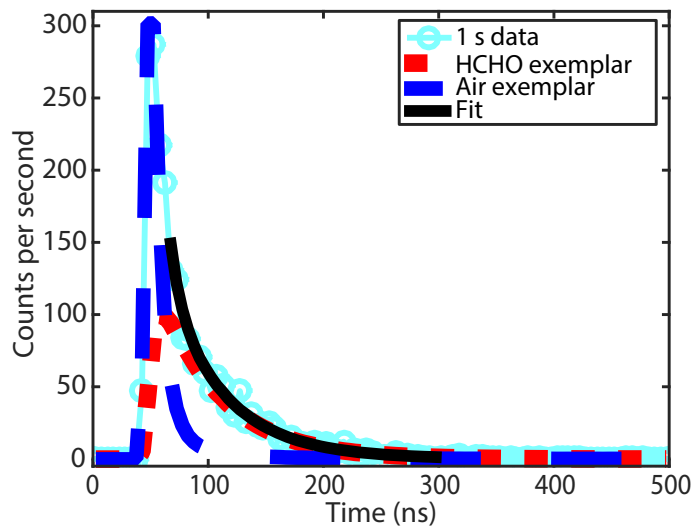

Figure 5. Each $1 \mathrm{~s}$ data profile (cyan circles) is fit using a linear combination of the air (dashed blue line) and HCHO (dashed red line). The fit profile, over the time window used for the least squares fit, is shown in black. The HCHO mixing ratio is 8 ppbv.

tion is performed on the data from bin 13 to bin 60 , with the fit window chosen to maximize data precision and fit quality, as determined by visual inspection of fit residuals. The optimized fit for the bin 13-60 window is shown in black.

\section{One-parameter exemplar fit}

The first step of the one-parameter fit applies a $21 \mathrm{~s}$ median filter to the vector of air exemplar fit scalars from the twoparameter fit. The smoothed vector is then used in a oneparameter fit where the air exemplar contribution is fixed to the air exemplar scaled by the smoothed vector, and the HCHO exemplar scaling factor is allowed to vary. The result is a higher precision fit and is possible because the phenomena that comprise the air exemplar contribution to the observed profile (chamber scatter, Raman and Rayleigh scatter, fluorescence of optics, etc.) do not change rapidly. The output of the one-parameter fit, the $\mathrm{HCHO}$ exemplar scalar, is directly proportional to $\mathrm{HCHO}$ mixing ratio. $\mathrm{HCHO}$ data in pptv are obtained by applying a calibration factor, which is unique to the $\mathrm{HCHO}$ exemplar used, to the fit output. The final $\mathrm{HCHO}$ mixing ratio data product is the arithmetic mean of the data from the two detection axes. Data from the two axes generally agree well - Fig. S4 shows the cross plot of $60 \mathrm{~s}$ data from the two axes, along with a linear fit (slope $=0.98$ ).

\subsubsection{Data processing with gated count data}

In addition to data processing with exemplar profiles, timegated $1 \mathrm{~Hz}$ data derived from the time-resolved profiles can be used to obtain $\mathrm{HCHO}$, with higher measurement precision than is achieved with the exemplar fits. For example, a calibration experiment yields, for $1 \mathrm{~s}$ data and $0 \mathrm{pptv}$ added $\mathrm{HCHO}$, standard deviations of $150 \mathrm{pptv}$ for the oneparameter exemplar fit (175 pptv for the two-parameter fit only) and $130 \mathrm{pptv}$ for the gated count data (167 pptv for ungated count data). The time-gated data exclude much of the prompt signal from scatter by summing counts from bin 24 to bin 100 (115 to $500 \mathrm{~ns})$. Using the same laboratory calibration experiment as an example, with no HCHO added, the gate excluded $89 \%$ (450 nm filter detection axis) and $95 \%$ (multi-band-pass axis) of the total signal in the first $500 \mathrm{~ns}$ from the trigger. More of the $\mathrm{HCHO}$ signal is retained due to its fluorescence lifetime: $73 \%$ of the HCHO signal is excluded by the gate. Figure S5 shows the time profile from Fig. 5 with the gate window shaded. Gated count $10 \mathrm{~Hz}$ data, as well as ungated count $10 \mathrm{~Hz}$ data, can be used to obtain HCHO mixing ratios. The $10 \mathrm{~Hz}$ data are used only for diagnostic purposes, e.g., the instrument flush time experiment in Sect. 4.4.

The count signal is converted to the $\mathrm{HCHO}$ mixing ratio using a linear relationship determined from laboratory calibrations, with the slope being the instrument sensitivity to HCHO (discussed in Sect. 4.1) and the intercept being the signal at $\mathrm{HCHO}=0 \mathrm{pptv}$, which was comprised of the same signal sources as the air exemplar: chamber scatter, Raman and Rayleigh scatter, and fluorescence of optics. While the count-derived HCHO data are of higher precision than the exemplar fit-derived $\mathrm{HCHO}$ data, the count-derived data are potentially more prone to measurement error from changes in background signal due to changes in alignment, degradation of optics, the presence of aerosol (Mie scattering), or from unknown fluorescing compounds. In contrast, ISAF (Cazorla et al., 2015) is immune to these changes in background due it its measurement of online and offline signal. Currently the count-derived HCHO data are only used for diagnostic purposes.

\section{Performance}

\subsection{Sensitivity}

The sensitivity of each detection axis to a given amount of $\mathrm{HCHO}$ is a function of a number of instrument parameters: laser power, collection optics efficiency, fluorescence optical filter transmission, and PMT response. As for ISAF, none of the instrument parameters that affect instrument sensitivity are expected to degrade on a timescale shorter than years. The HCHO calibration of the instrument has been measured 2-3 times per year and will be measured at least once a year in the future to track any changes in sensitivity.

Calibration is performed using measured flows from two cylinders, one containing ultra-high purity air further purified with a Drierite and molecular sieve scrubber and the other a $\sim 500$ ppbv mixture of $\mathrm{HCHO}$ in $\mathrm{N}_{2}$. The exact concentration of the HCHO mixture in all of our HCHO standard cylinders is measured yearly using infrared (IR) absorption, with less frequent verification of the IR measurement by long-path UV absorption. Details of the HCHO cylinder assessment via 


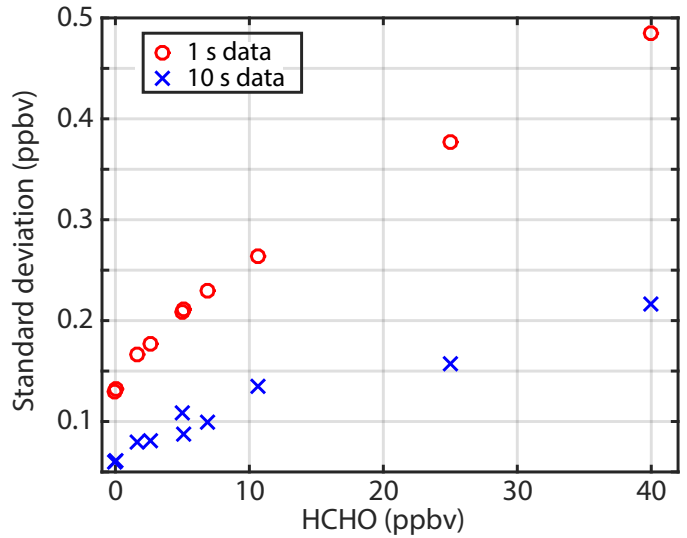

Figure 6. The standard deviation as a function of $\mathrm{HCHO}$ is shown to demonstrate the precision of the $\mathrm{HCHO}$ measurement for 1 and $10 \mathrm{~s}$ averaging.

IR and UV absorption are available in Cazorla et al. (2015). $\mathrm{HCHO}$ calibration accuracy for COFFEE is determined by the uncertainty in the $\mathrm{HCHO}$ standard concentration as well as the uncertainty in the gas flow dilution described below and is estimated to be $\pm 10 \%$.

For calibration, flow of the $\mathrm{HCHO}$ standard is sequentially set to 3-5 different flows in the range 0 50 standard $\mathrm{cm}^{3} \mathrm{~min}^{-1}(\mathrm{sccm})$ and is added to a carrier flow of UHP air, typically $3-5$ standard $\mathrm{L} \min ^{-1}$. The instrument draws $\sim 2.3$ standard $\mathrm{L} \mathrm{min}^{-1}$ and the remaining gas flow exhausts to the room before the pressure controller - the additional flow improves the time response of the calibration system. Typical calibration data for detection axis 2 are shown in Fig. S6.

Instrument sensitivity to HCHO differs for the two detection axes primarily due to their respective optical filter transmission, with axis 1 being more sensitive than axis 2. The gated count sensitivities for axis 1 and axis 2 are 0.29 and 0.13 counts $\mathrm{s}^{-1} \mathrm{~mW}^{-1} \mathrm{ppbv}^{-1}$, respectively. The ungated sensitivities for axis 1 and axis 2 are 0.98 and 0.47 counts $\mathrm{s}^{-1} \mathrm{~mW}^{-1} \mathrm{ppbv}^{-1}$, respectively. For comparison, the ISAF sensitivity is 75 counts $\mathrm{s}^{-1} \mathrm{~mW}^{-1} \mathrm{ppbv}^{-1}$ for its typical $100 \mathrm{mbar}$ operating pressure. Power-normalized sensitivities are significantly lower $(>100 \times)$ for COFFEE than the ISAF instruments primarily due to the less efficient overlap of the COFFEE laser output with the HCHO absorption lines.

\subsection{Precision}

Measurement precision is the dominant component of overall measurement uncertainty at low $(<700 \mathrm{pptv})$ mixing ratios. The standard deviation using data from two laboratory calibration experiments is shown in Fig. 6. At $[\mathrm{HCHO}]=0 \mathrm{ppbv}$, the precision is $\pm 130 \mathrm{pptv}$ in $1 \mathrm{~s}$ and $\pm 60 \mathrm{pptv}$ in $10 \mathrm{~s}$. Relative measurement precision improves

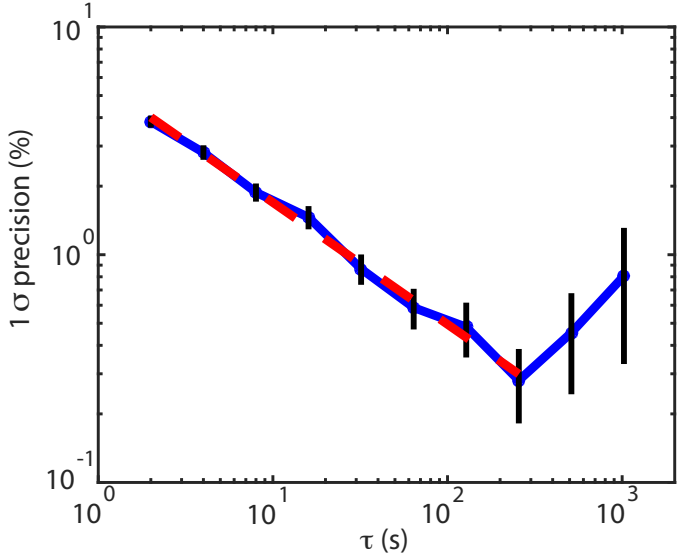

Figure 7. The normalized Allan-Werle deviation as a function of averaging time $(\tau)$ demonstrates the precision benefit of time averaging up to $250 \mathrm{~s}$. Fitting the data with $\tau<250 \mathrm{~s}$ yields a slope of -0.5 (dashed red line), which is consistent with white noise dominating the variability at shorter averaging periods. $[\mathrm{HCHO}]=5 \mathrm{ppbv}$.

with increasing $\mathrm{HCHO}$, as shown in Fig. S7 using the same calibration data. The largest source of noise for COFFEE HCHO is Raman and Raleigh scattering of the excitation beam by air. Chamber scatter accounts for $\sim 15 \%$ of the signal $\left(2\right.$ counts s $\left.\mathrm{s}^{-1} \mathrm{~mW}^{-1}\right)$ for axis 1 and $\sim 25 \%$ of the signal $\left(1\right.$ count s$\left.{ }^{-1} \mathrm{~mW}^{-1}\right)$ for axis 2 at $10.7 \mathrm{kPa}$ and $\mathrm{HCHO}=0 \mathrm{ppbv}$, with the remaining signal being from Raman and Raleigh scatter.

Precision should improve as data are time averaged. In practice, the benefit of additional time averaging ceases when the data variability is no longer dominated by random noise. The Allan-Werle deviation plot shown in Fig. 7 demonstrates this point for COFFEE HCHO data from a laboratory calibration with $\sim 5 \mathrm{ppbv} \mathrm{HCHO}$, processed with the two-parameter exemplar fit. The precision of the $\mathrm{HCHO}$ data improves with averaging until reaching a $250 \mathrm{~s}$ averaging time basis, implying that the signal-to-noise ratio for COFFEE measurements will improve from $1 \mathrm{~s}$ data to $10 \mathrm{~s}$ data and again to 1 min data. Fitting the decreasing linear (in log-log space) portion of the data yields a slope of -0.5 , which is consistent with the data variability being dominated by white noise on timescales shorter than $250 \mathrm{~s}$. The full fit-based data processing includes an additional step beyond the two-parameter fit, and a similar Allan-Werle deviation analysis gives a slope of -0.4 . The difference is likely due to the median filtering applied to the air exemplar scalar before conducting the oneparameter fit.

\subsection{Measurement uncertainty}

The overall measurement uncertainty for COFFEE HCHO is estimated to be $\pm(20 \%$ of $[\mathrm{HCHO}]+100 \mathrm{pptv})$. As discussed in Sect. 4.1, the calibration uncertainty is $\pm 10 \%$ of 


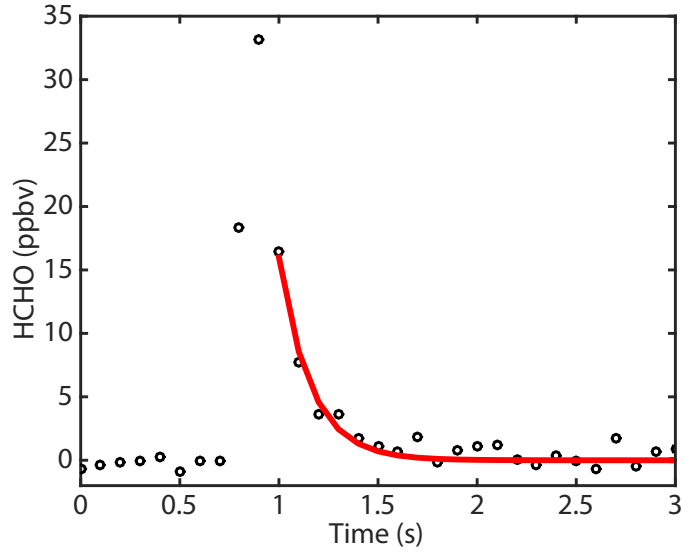

Figure 8. Instrument time response to a pulse of $\mathrm{HCHO}$ is fit with an exponential decay, giving an empirical $e$-fold flush time of $170 \mathrm{~ms}$.

[HCHO]. The additional $10 \%$ uncertainty is added to conservatively account for unquantified sources of error such as unknown signal sources other than $\mathrm{HCHO}$ and any fit biases. Additional and more extensive opportunities for instrument intercomparison in situ will likely reduce the need for this extra uncertainty. Currently no in-flight zeroing is performed for COFFEE. The 100 pptv term in the uncertainty is intended to account for any changes in the background signal over the $\sim 2 \mathrm{~h}$ duration AJAX flights. To date, we have not observed long time constant or high $\mathrm{HCHO}$ offset behavior with the COFFEE instrument that would be solved by in-flight zeroing.

\subsection{Time response}

Instrument time response directly affects the ability to resolve fine structure in atmospheric $\mathrm{HCHO}$ and can affect measurement accuracy in regions of high $\mathrm{HCHO}$ contrast such as biomass burning plumes. Understanding the instrument time response is critical to properly interpreting the in situ data. Assuming a volume of $60 \mathrm{~cm}^{3}$ and a volumetric flow of $29 \mathrm{~L} \mathrm{~min}^{-1}$ (2.3 standard $\mathrm{L} \mathrm{min}^{-1}, 303 \mathrm{~K}, 10.7 \mathrm{kPa}$ ), the $e$-fold flush time of COFFEE was estimated to be $125 \mathrm{~ms}$. The actual time response of the instrument was measured by introducing narrow time pulses of $\mathrm{HCHO}$ into the instrument and fitting the signal decay, as shown in Fig. 8. A lowvolume, rapidly switching valve (The Lee Company, IEP series) provided a $10 \mathrm{~ms}$ pulse of $\mathrm{HCHO}$ every 2 min into a flow of UHP air. The HCHO signal after the pulse was fit with an exponential decay, yielding an empirical $e$-fold flush time of 170, which is $45 \mathrm{~ms}$ slower than the flush time estimated from volume and flow rate alone. Typically the data rate reported by COFFEE is $1 \mathrm{~Hz}$, and therefore the $170 \mathrm{~ms}$ 1/e instrument response time will have a very limited effect on the observed $\mathrm{HCHO}$ data.

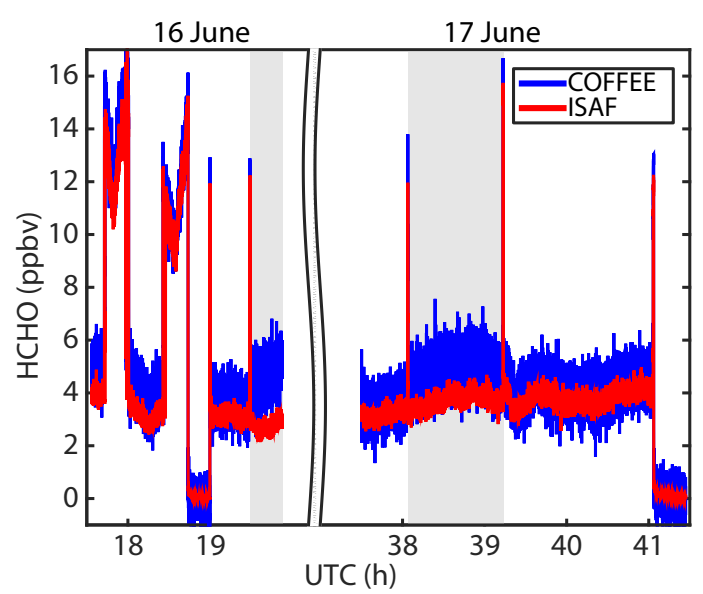

Figure 9. COFFEE (blue) and ISAF (red) data sampling from the roof of Building 33 at GSFC in June 2015. Shaded sections indicate COFFEE sampling without a particle filter. HCHO above 8 ppbv was from sampling indoor air, $\sim 4$ ppbv was ambient sampling, and $\sim 0$ ppbv was through a Drierite and molecular sieve scrubber.

\subsection{Measurement interference from aerosol}

Mie scattering from the presence of aerosol increases the prompt signal ( $<75 \mathrm{~ns}$ after trigger) detected by COFFEE. The additional prompt signal complicates the exemplar fitting routine by altering the profile shape of the non-HCHO component in the data time profile. To avoid the presence of Mie scattering, all ambient sampling with COFFEE is conducted through an in-line particle filter. An example of the error experienced by COFFEE from unfiltered ambient sampling is shown in Fig. 9. COFFEE and ISAF were installed in an office trailer on the roof of a NASA Goddard laboratory building, and both instruments sampled ambient air through the same $1 / 4^{\prime \prime}$ OD PFA tubing mounted on the roof of the trailer. With COFFEE sampling through the particle filter, the instruments agree well on sampling ambient air, room air, and scrubber-filtered air. The measurements do not agree as well, with a difference of $>1 \mathrm{ppbv}$, for periods of ambient sampling without a particle filter on COFFEE (shaded gray). The ISAF HCHO measurement is much less sensitive to the presence of particles due to its much lower $(\sim 25 \times)$ laser power, and utilizing a delayed gate for signal sampling is sufficient to exclude any artifact from scattering by particles.

\section{Field deployment}

\subsection{Alpha Jet integration}

COFFEE was designed specifically for integration onto the Alpha Jet (H211, LLC) stationed at the NASA Ames Research Center Moffett Field to participate in the Alpha Jet Atmospheric eXperiment (Hamill et al., 2016). The Alpha 


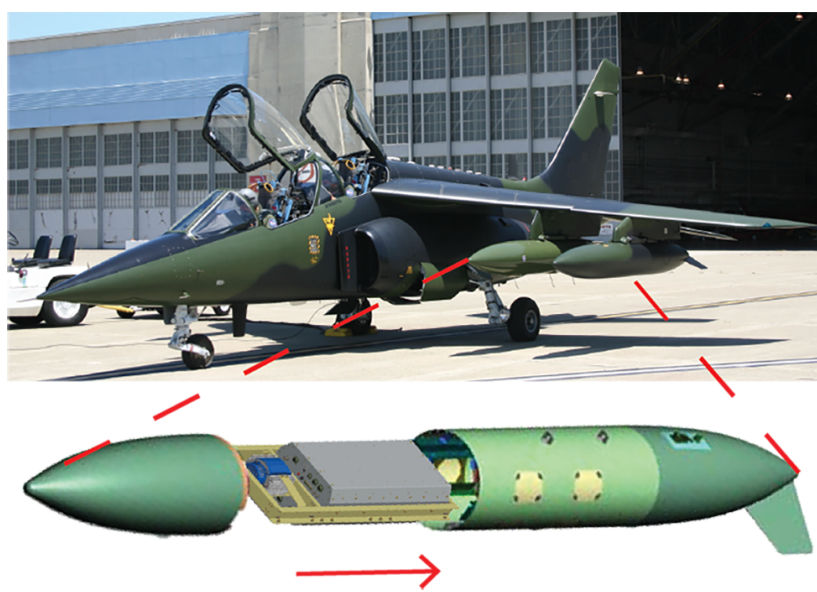

Figure 10. The COFFEE instrument, installed in its AJAX pod rack, is mounted into the mid-body of the inboard left pod.

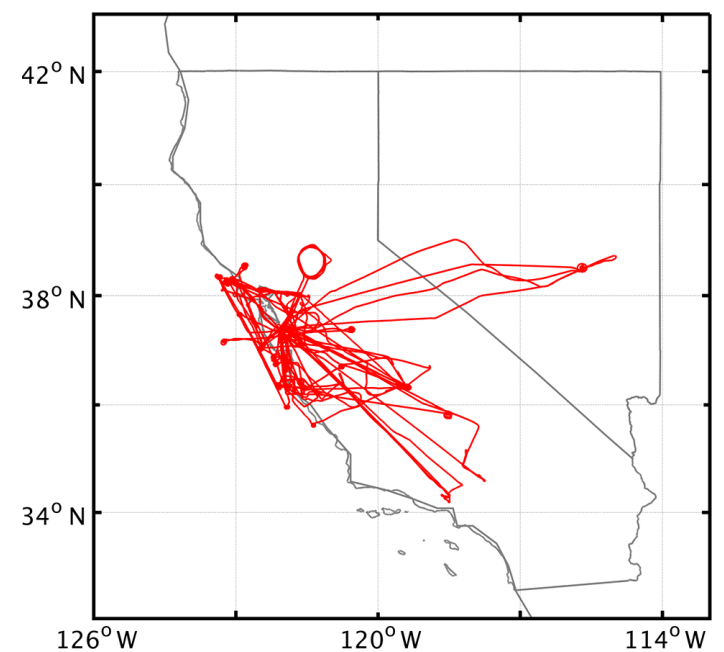

Figure 11. Map of AJAX flight tracks with COFFEE in payload through March 2017.

Jet carries four wing pods, with the outboard pods containing fuel and the inboard pods available for instrumentation. Each instrument wing pod has a usable volume of $\sim 0.1 \mathrm{~m}^{3}$ and a maximum payload weight of $136 \mathrm{~kg}$. COFFEE is mounted in the mid-body of the left wing pod, as shown in Fig. 10. The instrument chassis (Fig. 2, item F) and pump (Fig. 2, item D) attach to a rack designed for use in the wing pods (Fig. 2, item $\mathrm{G}$ ) and the rack then slides into the pod mid-body, making removal of the instrument straightforward for infrequent maintenance.

\subsection{Flight data}

The first flight of COFFEE on the Alpha Jet was on 15 December 2015. Since then, COFFEE has operated on 27 AJAX flights through March 2017, with data coverage predominately in the Bay Area and Central Valley of California. Fig-
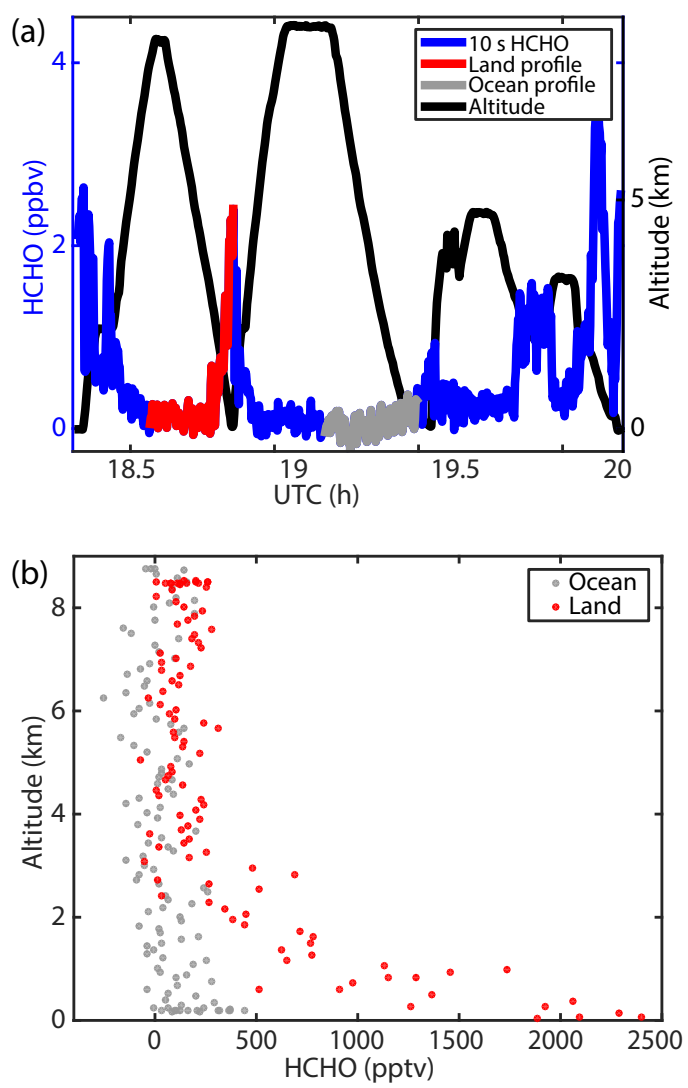

Figure 12. Flight data for AJAX flight 185 on 19 April 2006 (a) Time series of HCHO (10 s data, blue) and the corresponding aircraft altitude (black), with spiral profiles over land (red) and ocean (gray) highlighted. (b) Altitude profiles of HCHO (10 s data) over land (red) and ocean (gray).

ure 11 shows a map with overlaid flight tracks for all the AJAX flights with COFFEE, and Table S1 lists the dates and objectives for each of the 27 flights. During this period COFFEE returned to GSFC just three times for maintenance, typically timed to coincide with aircraft maintenance.

Data from AJAX flight 185 on 19 April 2016 are shown in Fig. 12 as an example of COFFEE HCHO performance. The flight included two spiral profiles, one over the San Joaquin Valley near Merced, CA $\left(37.38^{\circ} \mathrm{N}, 120.6^{\circ} \mathrm{W}\right)$, and one directly west, offshore over the Pacific Ocean $\left(37.17^{\circ} \mathrm{N}\right.$, $\left.123.2^{\circ} \mathrm{W}\right)$. The altitude profiles of $\mathrm{HCHO}$ for the two spirals are shown in the bottom panel of Fig. 12 for $10 \mathrm{~s}$ data. The onshore and offshore profiles are similar between 4 and $9 \mathrm{~km}$ and diverge considerably below $2 \mathrm{~km}$ as local photochemistry drives HCHO production over land. The profiles serve as a demonstration of the data set available for validation of HCHO satellite retrievals using routine AJAX flights over targeted profile locations. 


\section{Summary}

The NR-LIF technique utilized in COFFEE has proven to be a viable, operationally robust approach to measuring gasphase in situ HCHO. While not achieving the sensitivity of a state-selective LIF instrument such as ISAF (Cazorla et al., 2015), the NR-LIF technique provides adequate precision $(1 \sigma$ of $150 \mathrm{pptv}$ for $1 \mathrm{~s}$ data at 0 pptv $\mathrm{HCHO})$ for most scientific pursuits, with a lower-cost, highly reliable laser. COFFEE data from over two dozen AJAX flights spread over 15 months have demonstrated the potential utility of the aircraft platform for validation of satellite-based total column $\mathrm{HCHO}$.

Data availability. AJAX data are available upon request (Laura Iraci, laura.t.iraci@nasa.gov).

\section{The Supplement related to this article is available online at https://doi.org/10.5194/amt-10-4833-2017-supplement.}

Competing interests. The authors declare that they have no conflict of interest.

Acknowledgements. Funding was provided by the Goddard Internal Research and Development (IRAD) program and NASA (NNH16ZDA001N-UACO). J. E. Marrero gratefully acknowledges funding from the NASA Postdoctoral Program.

Edited by: Piero Di Carlo

Reviewed by: Alan Fried and one anonymous referee

\section{References}

Aiello, M. and McLaren, R.: Measurement of airborne carbonyls using an automated sampling and analysis system, Environ. Sci. Technol., 43, 8901-8907, https://doi.org/10.1021/es901892f, 2009.

Akagi, S. K., Yokelson, R. J., Wiedinmyer, C., Alvarado, M. J., Reid, J. S., Karl, T., Crounse, J. D., and Wennberg, P. O.: Emission factors for open and domestic biomass burning for use in atmospheric models, Atmos. Chem. Phys., 11, 4039-4072, https://doi.org/10.5194/acp-11-4039-2011, 2011.

Akagi, S. K., Burling, I. R., Mendoza, A., Johnson, T. J., Cameron, M., Griffith, D. W. T., Paton-Walsh, C., Weise, D. R., Reardon, J., and Yokelson, R. J.: Field measurements of trace gases emitted by prescribed fires in southeastern US pine forests using an open-path FTIR system, Atmos. Chem. Phys., 14, 199-215, https://doi.org/10.5194/acp-14-199-2014, 2014.

Anderson, L. G., Lanning, J. A., Barrell, R., Miyagishima, J., Jones, R. H., and Wolfe, P.: Sources and sinks of formaldehyde and acetaldehyde: An analysis of Denver's ambient concentration data,
Atmos. Environ., 30, 2113-2123, https://doi.org/10.1016/13522310(95)00175-1, 1996.

Andreae, M. O. and Merlet, P.: Emission of trace gases and aerosols from biomass burning, Glob. Biogeochem. Cy., 15, 955-966, https://doi.org/10.1029/2000GB001382, 2001.

Apel, E. C., Olson, J. R., Crawford, J. H., Hornbrook, R. S., Hills, A. J., Cantrell, C. A., Emmons, L. K., Knapp, D. J., Hall, S., Mauldin III, R. L., Weinheimer, A. J., Fried, A., Blake, D. R., Crounse, J. D., Clair, J. M. St., Wennberg, P. O., Diskin, G. S., Fuelberg, H. E., Wisthaler, A., Mikoviny, T., Brune, W., and Riemer, D. D.: Impact of the deep convection of isoprene and other reactive trace species on radicals and ozone in the upper troposphere, Atmos. Chem. Phys., 12, 1135-1150, https://doi.org/10.5194/acp-12-1135-2012, 2012.

Baidar, S., Oetjen, H., Coburn, S., Dix, B., Ortega, I., Sinreich, R., and Volkamer, R.: The CU Airborne MAX-DOAS instrument: vertical profiling of aerosol extinction and trace gases, Atmos. Meas. Tech., 6, 719-739, https://doi.org/10.5194/amt-6719-2013, 2013.

Catoire, V., Bernard, F., Mébarki, Y., Mellouki, A., Eyglunent, G., Daële, V., and Robert, C.: A tunable diode laser absorption spectrometer for formaldehyde atmospheric measurements validated by simulation chamber instrumentation, J. Environ. Sci., 24, 22 33, https://doi.org/10.1016/S1001-0742(11)60726-2, 2012.

Cazorla, M., Wolfe, G. M., Bailey, S. A., Swanson, A. K., Arkinson, H. L., and Hanisco, T. F.: A new airborne laser-induced fluorescence instrument for in situ detection of formaldehyde throughout the troposphere and lower stratosphere, Atmos. Meas. Tech., 8, 541-552, https://doi.org/10.5194/amt-8-541-2015, 2015.

Chance, K., Palmer, P. I., Spurr, R. J. D., Martin, R. V., Kurosu, T. P., and Jacob, D. J.: Satellite observations of formaldehyde over North America from GOME, Geophys. Res. Lett., 27, 34613464, https://doi.org/10.1029/2000GL011857, 2000.

Co, D. T., Hanisco, T. F., Anderson, J. G., and Keutsch, F. N.: Rotationally resolved absorption cross sections of formaldehyde in the $28100-28500 \mathrm{~cm}^{-1}$ (351-356 nm) spectral region: implications for in situ LIF measurements, J. Phys. Chem., 109, 1067510682, https://doi.org/10.1021/jp053466i, 2005.

Fried, A., Crawford, J., Olson, J., Walega, J., Potter, W., Wert, B., Jordan, C., Anderson, B., Shetter, R., Lefer, B., Blake, D., Blake, N., Meinardi, S., Heikes, B., O’Sullivan, D., Snow, J., Fuelberg, H., Kiley, C. M., Sandholm, S., Tan, D., Sachse, G., Singh, H., Faloona, I., Harward, C. N., and Carmichael, G. R.: Airborne tunable diode laser measurements of formaldehyde during TRACEP: Distributions and box model comparisons, J. Geophys. Res., 108, 8798, https://doi.org/10.1029/2003JD003451, 2003.

Fried, A., Walega, J. G., Olson, J. R., Crawford, J. H., Chen, G., Weibring, P., Richter, D., Roller, C., Tittel, F. K., Heikes, B. G., Snow, J. A., Shen, H., O’Sullivan, D. W., Porter, M., Fuelberg, H., Halland, J., and Millet, D. B.: Formaldehyde over North America and the North Atlantic during the summer 2004 INTEX campaign: Methods, observed distributions, and measurement-model comparisons, J. Geophys. Res. Atmos., 113, 1-16, https://doi.org/10.1029/2007JD009185, 2008a.

Fried, A., Olson, J. R., Walega, J. G., Crawford, J. H., Chen, G., Weibring, P., Richter, D., Roller, C., Tittel, F., Porter, M., Fuelberg, H., Halland, J., Bertram, T. H., Cohen, R. C., Pickering, K., Heikes, B. G., Snow, J. A., Shen, H., O'Sullivan, D. W., Brune, W. H., Ren, X., Blake, D. R., Blake, N., Sachse, G., 
Diskin, G. S., Podolske, J., Vay, S. A., Shetter, R. E., Hall, S. R., Anderson, B. E., Thornhill, L., Clarke, A. D., McNaughton, C. S., Singh, H. B., Avery, M. A., Huey, G., Kim, S., and Millet, D. B.: Role of convection in redistributing formaldehyde to the upper troposhere over Noth Atlantic during the summer 2004 INTEX campaign, J. Geophys. Res. Atmos., 113, 1-19, https://doi.org/10.1029/2007JD009760, 2008b.

Fried, A., Barth, M. C., Bela, M., Weibring, P., Richter, D., Walega, J., Li, Y., Pickering, K., Apel, E., Hornbrook, R., Hills, A., Riemer, D. D., Blake, N., Blake, D. R., Schroeder, J. R., Luo, Z. J., Crawford, J. H., Olson, J., Rutledge, S., Betten, D., Biggerstaff, M. I., Diskin, G. S., Sachse, G., Campos, T., Flocke, F., Weinheimer, A., Cantrell, C., Pollack, I., Peischl, J., Froyd, K., Wisthaler, A., Mikoviny, T., and Woods, S.: Convective transport of formaldehyde to the upper troposphere and lower stratosphere and associated scavenging in thunderstorms over the central United States during the 2012 DC3 study, J. Geophys. Res. Atmos., 121, 7430-7460, https://doi.org/10.1002/2015JD024477, 2016.

Hagopian, J.: Carbon nanotubes for stray light suppression, Art. 9417, NASA Tech. Briefs, 2011.

Hak, C., Pundt, I., Trick, S., Kern, C., Platt, U., Dommen, J., Ordóñez, C., Prévôt, A. S. H., Junkermann, W., Astorga-Lloréns, C., Larsen, B. R., Mellqvist, J., Strandberg, A., Yu, Y., Galle, B., Kleffmann, J., Lörzer, J. C., Braathen, G. O., and Volkamer, R.: Intercomparison of four different in-situ techniques for ambient formaldehyde measurements in urban air, Atmos. Chem. Phys., 5, 2881-2900, https://doi.org/10.5194/acp-5-2881-2005, 2005.

Hamill, P., Iraci, L. T., Yates, E. L., Gore, W., Bui, T. P., Tanaka, T., and Loewenstein, M.: A new instrumented airborne platform for atmospheric research, Bull. Am. Meteorogical Soc., 97, 397404, https://doi.org/10.1175/BAMS-D-14-00241.1, 2016.

Hottle, J. R., Huisman, A. J., Digangi, J. P., Kammrath, A., Galloway, M. M., Coens, K. L., and Keutsch, F. N.: Fluorescence-based instrument for in-situ measurements of atmospheric formaldehyde, Environ. Sci. Technol., 43, 790-795, https://doi.org/10.1021/es801621f, 2009.

Jaeglé, L., Jacob, D. J., Brune, W. H., and Wennberg, P. O.: Chemistry of HOx radicals in the upper troposphere, Atmos. Environ., 35, 469-489, https://doi.org/10.1016/S1352-2310(00)00376-9, 2001.

Junkermann, W. and Burger, J. M.: A new portable instrument for continuous measurement of formaldehyde in ambient air, J. Atmos. Ocean. Technol., 23, 38-45, https://doi.org/10.1175/JTECH1831.1, 2006.

Kaiser, J., Li, X., Tillmann, R., Acir, I., Holland, F., Rohrer, F., Wegener, R., and Keutsch, F. N.: Intercomparison of Hantzsch and fiber-laser-induced-fluorescence formaldehyde measurements, Atmos. Meas. Tech., 7, 1571-1580, https://doi.org/10.5194/amt7-1571-2014, 2014.

Lazrus, A. L., Fong, K. L., and Lind, J. A.: Automated fluorometric determination of formaldehyde in air, Anal. Chem., 60, 10741078, https://doi.org/10.1021/ac00161a025, 1988.

Luecken, D. J., Hutzell, W. T., Strum, M. L., and Pouliot, G. A.: Regional sources of atmospheric formaldehyde and acetaldehyde, and implications for atmospheric modeling, Atmos. Environ., 47, 477-490, https://doi.org/10.1016/j.atmosenv.2011.10.005, 2012.
Mohlmann, G. R.: Formaldehyde detection in air by laserinduced fluorescence, Appl. Spectrosc., 39, 98-101, https://doi.org/10.1366/0003702854249088, 1985.

Olaguer, E. P., Rappenglück, B., Lefer, B., Stutz, J., Dibb, J., Griffin, R., Brune, W. H., Shauck, M., Buhr, M., Jeffries, H., Vizuete, W., and Pinto, J. P.: Deciphering the role of radical precursors during the Second Texas Air Quality Study, J. Air Waste Manag. Assoc., 59, 1258-1277, https://doi.org/10.3155/1047-3289.59.11.1258, 2009.

Palmer, P. I., Jacob, D. J., Fiore, A. M., Martin, R. V., Chance, K., and Kurosu, T. P.: Mapping isoprene emissions over North America using formaldehyde column observations from space, J. Geophys. Res., 108, 1984-2012, https://doi.org/10.1029/2002JD002153, 2003.

Parrish, D. D., Ryerson, T. B., Mellqvist, J., Johansson, J., Fried, A., Richter, D., Walega, J. G., Washenfelder, R. A., de Gouw, J. A., Peischl, J., Aikin, K. C., McKeen, S. A., Frost, G. J., Fehsenfeld, F. C., and Herndon, S. C.: Primary and secondary sources of formaldehyde in urban atmospheres: Houston Texas region, Atmos. Chem. Phys., 12, 3273-3288, https://doi.org/10.5194/acp12-3273-2012, 2012.

Richter, D., Weibring, P., Walega, J. G., Fried, A., Spuler, S. M., and Taubman, M. S.: Compact highly sensitive multi-species airborne mid-IR spectrometer, Appl. Phys. B Lasers Opt., 119, 119131, https://doi.org/10.1007/s00340-015-6038-8, 2015.

Shim, C., Wang, Y., Choi, Y., Palmer, P. I., Abbot, D. S., and Chance, K.: Constraining global isoprene emissions with Global Ozone Monitoring Experiment (GOME) formaldehyde column measurements, J. Geophys. Res., 110, D24301, https://doi.org/10.1029/2004JD005629, 2005.

Steck, T., Glatthor, N., von Clarmann, T., Fischer, H., Flaud, J. M., Funke, B., Grabowski, U., Höpfner, M., Kellmann, S., Linden, A., Perrin, A., and Stiller, G. P.: Retrieval of global upper tropospheric and stratospheric formaldehyde $\left(\mathrm{H}_{2} \mathrm{CO}\right)$ distributions from high-resolution MIPAS-Envisat spectra, Atmos. Chem. Phys., 8, 463-470, https://doi.org/10.5194/acp-8-4632008, 2008.

Warneke, C., Veres, P., Holloway, J. S., Stutz, J., Tsai, C., Alvarez, S., Rappenglueck, B., Fehsenfeld, F. C., Graus, M., Gilman, J. B., and de Gouw, J. A.: Airborne formaldehyde measurements using PTR-MS: Calibration, humidity dependence, intercomparison and initial results, Atmos. Meas. Tech., 4, 23452358, https://doi.org/10.5194/amt-4-2345-2011, 2011.

Washenfelder, R. A., Attwood, A. R., Flores, J. M., Zarzana, K. J., Rudich, Y., and Brown, S. S.: Broadband cavity-enhanced absorption spectroscopy in the ultraviolet spectral region for measurements of nitrogen dioxide and formaldehyde, Atmos. Meas. Tech., 9, 41-52, https://doi.org/10.5194/amt-9-41-2016, 2016.

Weibring, P., Richter, D., Fried, A., Walega, J. G., and Dyroff, C.: Ultra-high-precision mid-IR spectrometer II: system description and spectroscopic performance, Appl. Phys. B Lasers Opt., 85, 207-218, https://doi.org/10.1007/s00340-006-2300-4, 2006.

Wert, B. P., Fried, A., Henry, B., and Cartier, S.: Evaluation of inlets used for the airborne measurement of formaldehyde, J. Geophys. Res. Atmos., 107, 4163, https://doi.org/10.1029/2001JD001072, 2002.

Yokelson, R. J., Goode, J. G., Ward, D. E., Susott, R. A., Babbitt, R. E., Wade, D. D., Bertschi, I., Griffith, D. W. T., and Hao, W. M.: Emissions of formaldehyde, acetic acid, methanol, and 
other trace gases from biomass fires in North Carolina measured by airborne Fourier transform infrared spectroscopy, J. Geophys. Res., 104, 30109-30125, https://doi.org/10.1029/1999jd900817, 1999.

Zhu, L., Jacob, D. J., Kim, P. S., Fisher, J. A., Yu, K., Travis, K. R., Mickley, L. J., Yantosca, R. M., Sulprizio, M. P., De Smedt, I., González Abad, G., Chance, K., Li, C., Ferrare, R., Fried, A., Hair, J. W., Hanisco, T. F., Richter, D., Jo Scarino, A., Walega, J., Weibring, P., and Wolfe, G. M.: Observing atmospheric formaldehyde ( $\mathrm{HCHO}$ ) from space: validation and intercomparison of six retrievals from four satellites (OMI, GOME2A, GOME2B, OMPS) with SEAC ${ }^{4}$ RS aircraft observations over the southeast US, Atmos. Chem. Phys., 16, 1347713490, https://doi.org/10.5194/acp-16-13477-2016, 2016. 